\section{Verrucous Carcinoma of the Esophagus}

C. Ereño ${ }^{1}$, J. L. Lopez ${ }^{1}$,

A. Loizate ${ }^{2}$, F. J. Bilbao ${ }^{2}$

${ }^{1}$ Dept. of Pathology, Hospital de Basurto, Basque Country University, Bilbao, Spain

${ }^{2}$ Dept. of Digestive Surgery, Hospital de Basurto, Basque Country University, Bilbao, Spain

Corresponding Author

C. Ereño

Dept. of Pathology

Hospital de Basurto

Avda. de Montevideo 18

48013 Bilbo

Spain

Fax: $\quad+94-400-6180$

E-mail: cereno@hbas.osakidetza.net

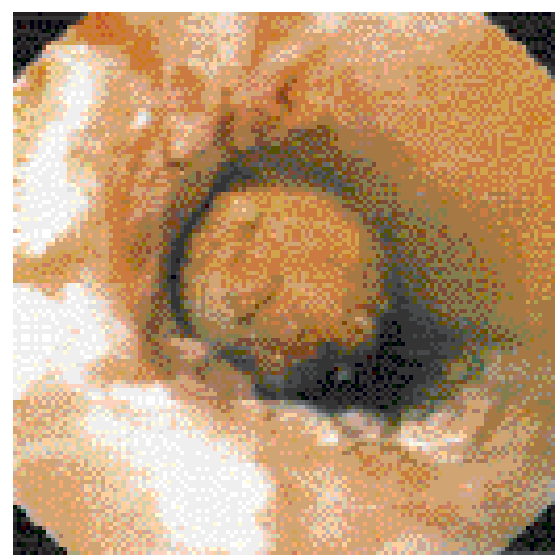

Figure 1 A 65-year-old woman presented with a history of longstanding dysphagia. During endoscopy, a stenosing verrucous lesion was found in the middle third of the esophagus.

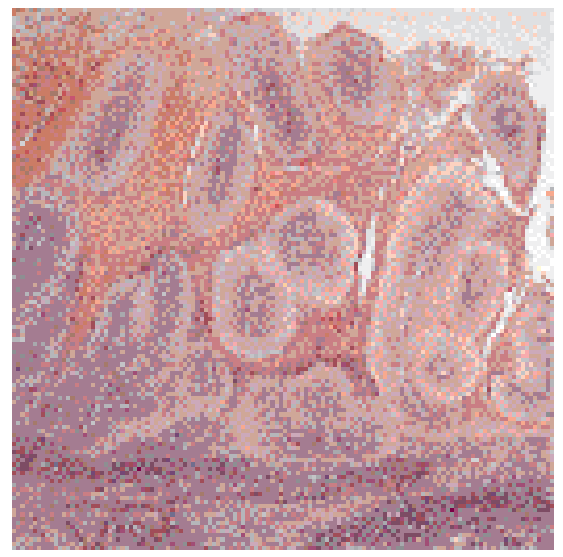

Figure 3 Histologically, the tumor was composed of non-branching, filiform papillae with a thick layer of parakeratosis on the surface. In depth, the neoplasm showed a pushing border.

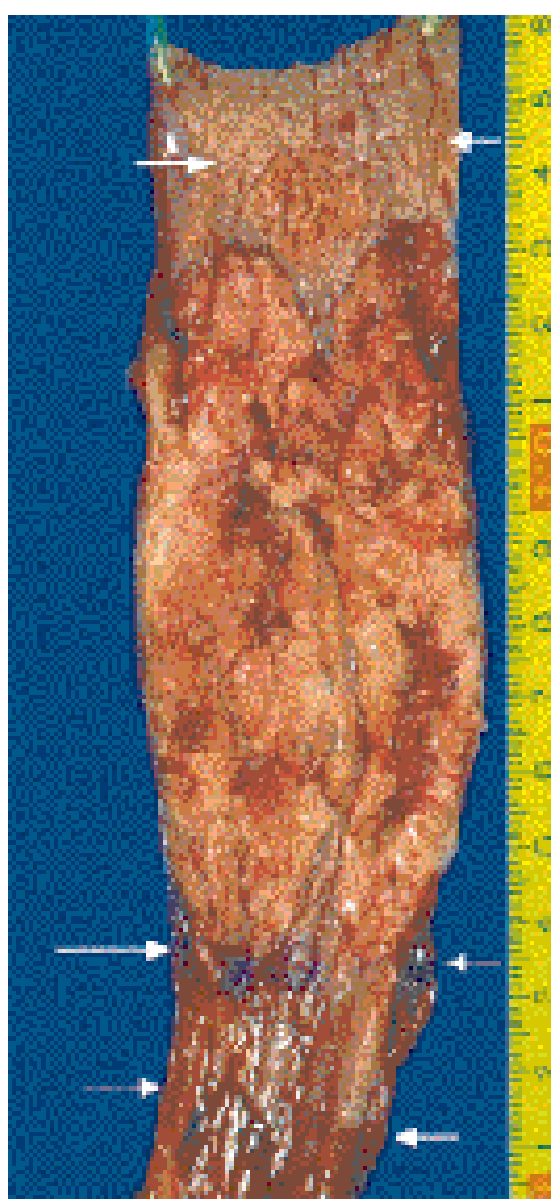

Figure 2 The esophagogastrectomy specimen revealed a reddish, plate-like, exophytic tumor, $11 \mathrm{~cm}$ in length, located at $2.5 \mathrm{~cm}$ from the cardioesophageal junction. 